\title{
Comportamento meiótico e viabilidade polínica na espécie Jatropha curcas L.
}

\section{Meiotic behavior and pollen viability in Jatropha curcas L.}

\author{
Isabela Pereira Diegues ${ }^{1}$; Pedro Corrêa Damasceno Junior ${ }^{2 *}$; Nathália Virgínia da \\ Silva Ribeiro ${ }^{3}$; Marcus Vinicius Magro Reis ${ }^{4}$; Antônio Carlos de Souza Abboud ${ }^{5}$
}

\section{Resumo}

\begin{abstract}
A espécie Jatropha curcas, conhecida como pinhão-manso, pertencente à família Euphorbiaceae, figura atualmente como uma das oleaginosas de maior potencial para a produção de biodiesel no Brasil. O presente estudo teve como objetivo avaliar a meiose e a viabilidade polínica em acessos de $J$. curcas que compõem a coleção de germoplasma da UFRRJ. Para tal, foram coletados botões florais de 20 plantas, a seguir estes foram fixados em solução de ácido acético 3:1 e álcool 70\%. A coloração das células foi feita através dos corantes carmim acético $2 \%$ e da solução tripla de Alexander, para as análises meióticas e de viabilidade polínica, respectivamente. Todas as observações foram realizadas em microscópio óptico. Foi observado que a espécie possui $2 \mathrm{n}=2 \mathrm{x}=22$ cromossomos. Foram observadas várias irregularidades durante a divisão meiótica, como a presença de cromossomos pegajosos, produtos meióticos irregulares, como mônades, díades, tríades e políades, além da ocorrência de citomixia e micronúcleos, sendo que estas duas últimas anomalias tiveram maior frequência entre os acessos avaliados. O índice meiótico foi estimado em $84,21 \%$ e a média da viabilidade polínica em $89,85 \%$. A menor viabilidade polínica foi de 78\% (UFRRJ885), enquanto que a máxima observada foi de 96\% (UFRRJ861). Com base nos resultados obtidos, apesar de Jatropha curcas apresentar certas anomalias durante a meiose, os acessos aqui analisados mostraram viabilidade polínica satisfatória.
\end{abstract}

Palavras-chave: Citomixia, índice meiótico, irregularidade meiótica, meiose

\begin{abstract}
The Jatropha curcas, known as physic nut, belonging to the Euphorbiaceae family, figure today as one of the greatest potential of oilseeds for biodiesel production in Brazil. The present study aimed to evaluate meiosis and pollen viability in $J$. curcas accesses from UFRRJ germplasm collection. To do that, flower buds were collected from 20 plants, these were fixed in acetic acid 3:1 solution and alcohol $70 \%$. The staining of the cells was done by acetic carmine $2 \%$ solution and Alexander's triple solution, for the analysis of meiotic and pollen viability, respectively. All observations were carried out under an optical microscope. It was observed that the species has $2 \mathrm{n}=2 \mathrm{x}=22$ chromosomes. It was observed many irregularities during the meiotic division as the presence of sticky chromosomes and irregular meiotic products, such as monads, dyads, triads and polyads, and the occurrence of cytomixis and micronucleus, these latter two anomalies had a higher frequency among the accessions. The meiotic
\end{abstract}

1 Bióloga, Discente de doutorado do Programa de Pós-Graduação em Fitotecnia, Universidade Federal Rural do Rio de Janeiro, UFRRJ, Seropédica, RJ. E-mail: dieguesisabela@hotmail.com

2 Prof. Adjunto, Dept ${ }^{\circ}$ de Fitotecnia, Instituto de Agronomia, UFRRJ, Seropédica, RJ. E-mail: damascenojunior@gmail.com

3 Licenciada em Ciências Agrícolas, M.e em Fitotecnia pelo Programa de Pós-Graduação em Fitotecnia, UFRRJ, Seropédica, RJ. E-mail: nathalia-vsr@bol.com.br

4 Eng ${ }^{\mathrm{o}}$ Agr ${ }^{\circ}$., M.e em Fitotecnia pelo Programa de Pós-Graduação em Fitotecnia, UFRRJ, Seropédica, RJ. E-mail: marcus.ufrrj@ gmail.com

5 Prof. Associado, Dept ${ }^{\circ}$ de Fitotecnia, Instituto de Agronomia, UFRRJ, Seropédica, RJ. E-mail: abboud@ufrrj.br

* Autor para correspondência 
index was estimated in $84.21 \%$ and the average pollen viability in $89.85 \%$. The lowest pollen viability was $78 \%$ (UFRRJ885), while the maximum observed was 96\% (UFRRJ861). Based on the results obtained, although Jatropha curcas presents certain anomalies during meiosis, the accessions analyzed here showed satisfactory pollen viability.

Key words: Cytomixis, meiotic index, meiotic irregularities, meiosis

\section{Introdução}

O gênero Jatropha, pertencente à família Euphorbiaceae, possui cerca de 175 espécies identificadas (DEHGAN; WEBSTER, 1979). Dentre elas, a espécie Jatropha curcas L., conhecida como pnhão-manso ou "physic nut", se destaca pela excelente qualidade do óleo para a produção de biodisel (DRUMOND et al., 2010; HELLER, 1996). No Brasil, o pinhão-manso pode ser encontrado do nordeste até o estado do Paraná (ARRUDA et al., 2004), na região sul do país. De acordo com Heller (1996), o provável centro de origem de J. curcas é a América Central, possivelmente o México, porém tal informação é ainda bastante discutida.

Apesar do grande potencial para produção de biodiesel, o pinhão-manso ainda se encontra em fase inicial de domesticação, desse modo, não existem materiais geneticamente melhorados, sobre os quais se tenha garantias de sua produção e potencialidade adaptativa (ACHTEN et al., 2010). Culturas em que o objetivo principal é a produção de sementes, como é o caso do pinhão-manso, seu sucesso está proximamente ligado à disponibilidade e viabilidade de grãos de pólen nas plantas. Em estudo realizado por Bione, Pagliarini e Toledo (2000), em soja, atenta-se para o fato de que o declínio da produção de sementes estaria correlacionado com irregularidades meióticas. Dessa forma, estudos básicos, referentes ao comportamento meiótico e à viabilidade polínica, poderão auxiliar programas de melhoramento genético em pinhão-manso.

De acordo com Carvalho et al. (2008), o pinhãomanso possui genoma pequeno, com conteúdo $2 \mathrm{C}$ de $0,85 \mathrm{pg}$, possuindo 22 cromossomos, dos tipos metacêntricos e submetacêntricos, com tamanho relativamente pequeno, variando entre 1,24 e $1,71 \mu \mathrm{m}$. Conforme Dahmer, Wittmann e Dias (2009), a falta de variação no número de cromossomos contrasta com a alta variabilidade fenotípica encontrada dentro da espécie, como por exemplo, as concentrações de ésteres de forbol e do conteúdo de óleo nas sementes. No âmbito molecular, a diversidade genética em pinhãomanso já foi bastante explorada por diversos tipos de marcadores. Estudos realizados por Sun et al. (2008), utilizando marcadores AFLP (Amplified Fragment Length Polymorphism) e SSR (Simple Sequence Repeat), demonstraram a espécie possui uma base genética estreita. Tal dado foi corroborado por Rosado et al. (2010), empregando marcadores SSR e RAPD (Random Amplified Polymorphic $D N A$ ), na genotipagem de 192 acessos brasileiros de pinhão-manso.

$\mathrm{O}$ estudo meiótico em espécies ainda não melhoradas ou em fase de melhoramento se faz altamente importante. De acordo com Damasceno Junior et al. (2010), é esperado que espécies não melhoradas geneticamente, sendo estas ainda em estado silvestre ou pouco domesticadas, apresentem comportamento meiótico oscilante entre os genótipos e muitas irregularidades nas fases da meiose e pós-meiose, o que poderá resultar em uma fertilidade limitada quando se considera gametas masculinos. Também, conforme Horner e Palmer (1995) o surgimento de grãos de pólen anormais, ou inviáveis, pode ser resultado de aberrações estruturais e numéricas, que por sua vez, decorrem de anormalidades que podem ocorrer durante a prémeiose, meiose e pós-meiose.

Estudos de estabilidade meiótica e viabilidade dos grãos de pólen permitem indicar o potencial de cruzamento da planta (LOVE, 1951). Biondo e Battistin (2001) inferem que o estudo da viabilidade polínica se constitui em um dos fatores de suma 
importância no melhoramento vegetal, pois através dele é possivel verificar a potencialidade do gameta masculino na eficiência da fecundação e sua posterior fertilização. Por meio dos dados de viabilidade polínica, é possível obter correlações com anormalidades meióticas, auxiliar na seleção de materiais genéticos e fazer inferências sobre a eficiência de cruzamentos.

Em face do contexto apresentado, visando auxiliar programas de melhoramento de pinhãomanso, este trabalho teve por objetivo conhecer o comportamento meiótico da espécie, a partir de acessos conservados na coleção de germoplasma da Universidade Federal Rural do Rio de Janeiro (UFRRJ), estimando ainda seu índice meiótico, índice de recombinação e sua viabilidade polínica.

\section{Material e Métodos}

\section{Material vegetal}

Os acessos de pinhão manso avaliados no presente trabalho são conservados na Coleção de germoplasma, sendo constituída por plantas em desenvolvimento direto no campo do Departamento de Fitotecnia do Instituto de Agronomia da Universidade Federal Rural do Rio de Janeiro (UFRRJ), localizada no campus de Seropédica, no Estado do Rio de Janeiro. A coleção é composta por acessos de diferentes localidades do Brasil e do exterior. A coleta dos botões florais foi realizada em plantas de 1,4 anos de idade.

\section{Análise meiótica: observação das irregularidades}

Botões florais de diferentes tamanhos foram coletados em bulk a partir de 20 plantas selecionadas aleatoriamente no campo e fixados em solução de etanol e ácido acético na proporção de 3:1, e armazenados em freezer até o momento do uso. Os botões florais foram dissecados em microscópio estereoscópio (BEL Photonics, modelo $\mathrm{SZT}$ ), tendo todas as anteras do botão retiradas, e abertas em uma gota de carmim acético 2\% para liberação das células. Em seguida foram retirados os debrís e a lâmina foi montada. A observação e análise das células foi realizada em microscópio óptico (BEL Photonics, modelo Bio 3 Research) utilizando-se o campo claro. Todas as imagens aqui apresentadas foram obtidas em câmera digital de alta resolução (BEL Photonics USB 9MP) acoplada ao microscópio. Observou-se e quantificou-se todas as irregularidades meióticas que ocorreram durante o ciclo celular. Também foram vistos o número de cromossomos e o nível de ploidia da espécie em estudo, bem como o número de pares cromossômicos associados ao nucléolo. Estimou-se o índice de recombinação (IR) na espécie, de acordo com a expressão proposta por Darlington (1958), onde $\mathrm{IR}=[$ å número total de quiasmas $\div$ número total de células analisadas] + valor $n$ (número de cromossomos).

Análise dos produtos meióticos: estimação do índice meiótico

Nesta análise trabalhou-se com botões florais maiores que os da análise meiótica, em fase anterior a antese. Estes foram coletados em bulk nas mesmas 20 plantas utilizadas para a análise meiótica, e fixados em solução de etanol e ácido acético na proporção de 3:1. Em seguida, os frascos contendo as amostras foram armazenados em freezer até o início das observações em microscópio. Os botões florais foram dissecados em microscópio estereoscópio (BEL Photonics, modelo SZT), tendo apenas 4 anteras retiradas e maceradas em uma gota de carmim acético $2 \%$ para liberação das células. Em seguida as lâminas foram montadas e levadas para análise em campo claro em microscópio óptico (BEL Photonics, modelo Bio 3 Research). As imagens obtidas em microscópio foram capturadas em câmera digital de alta resolução (BEL Photonics USB 9MP) acoplada a este equipamento.

Para a estimação do índice meiótico (IM), quantificou-se o número de produtos pós-meióticos, 
denominados: mônades, díades, tríades, tétrades e políades. Para o cálculo, utilizou-se a expressão proposta por Love (1951), onde IM = [(número total de tétrades normais), (número total de mônades + díades + tríades + tétrades + políades $)]$ x 100.

\section{Análise da viabilidade dos grãos de pólen}

As análises de viabilidade polínica foram realizadas em 20 plantas da coleção de germoplasma da UFRRJ, identificados por acesso e provenientes de 6 procedências, como a seguir: Janaúba, MG (UFRRJ346; UFRRJ828; UFRRJ858; UFRRJ859; UFRRJ861; UFRRJ863; UFRRJ872; UFRRJ874; UFRRJ875; UFRRJ885; UFRRJ899), Petrolina, PE (UFRRJ831; UFRRJ832; UFRRJ836), Dourados, MS (UFRRJ805; UFRRJ932), Rio das Flores, RJ (UFRRJ321; UFRRJ362), Guapimirim, RJ (UFRRJ370) e Rio Verde, GO (UFRRJ318).

Os botões florais coletados nos acessos acima mencionados foram fixados em etanol $70 \%$ e conservados em geladeira até o preparo das lâminas. Os botões foram dissecados em microscópio estereoscópio (BEL Photonics, modelo SZT). Utilizou-se quatro anteras/botão/lâmina, e em seguida, estas foram maceradas em uma gota de Solução Tripla de Alexander (ALEXANDER, 1969) para liberação dos grãos de pólen na lâmina. Em seguida, a lâmina foi montada e observada em microscópio óptico (BEL Photonics, modelo Bio 3 Research). Grãos de pólen viáveis/férteis foram detectados pela presença da coloração vermelha, enquanto que os grãos de pólen inviáveis apresentaram coloração verde. As imagens dos grãos de pólen viáveis e inviáveis foram capturadas em câmera digital de alta resolução (BEL Photonics USB 9MP) acoplada ao microscópio.

Foram coletados 10 botões florais por planta, sendo utilizadas 20 plantas nesta análise. Cada lâmina montada e avaliada correspondeu a um botão floral, dessa forma, analisou-se 10 lâminas/planta, contando-se 400 grãos de pólen/lâmina. Ao todo foram contados 80.000 grãos de pólen. Por último, foi calculada a média da porcentagem de grãos de pólen viáveis em cada genótipo.

\section{Resultados e Discussão}

\section{Comportamento meiótico}

No presente estudo, observou-se que a espécie é diplóide, $\operatorname{com} 2 \mathrm{n}=2 \mathrm{x}=22$ cromossomos (Figura 1A). Esses dados estão de acordo com os resultados encontrados por Dahmer, Wittmann e Dias (2009) e Sasikala e Paramathma (2010). Baseando-se em caracteres cromossômicos morfométricos, Carvalho et al. (2008) sugerem que o pinhão-manso possa se tratar de uma espécie autotetraplóide, porém, até o presente momento, esses resultados não são suportados pelos resultados obtidos nem no presente trabalho e nem por todos os autores anteriormente citados. Porém, todos os indivíduos aqui analisados apresentaram padrão único, ou semelhante, quanto ao número de cromossomos. Havendo esta última situação nos casos em que não foi possível inferir de forma segura sobre o número de cromossomos encontrados em determinada célula. De qualquer forma, mais estudos citogenéticos sobre a espécie e o gênero Jatropha são ainda necessários. Por todos os genótipos analisados serem diplóides, Dahmer, Wittmann e Dias (2009) mencionam que esta ocorrência pode ser de grande vantagem em trabalhos de melhoramento genético da espécie, visto que cruzamentos poderão ser planejados de forma a obter híbridos férteis.

Sasikala e Paramathma (2010) estudando nove espécies do gênero Jatropha, incluindo $J$. curcas, concluíram que apenas a espécie $J$. villosa não apresentou número básico cromossômico igual a 11, mas igual a 10, portanto, ao invés de 22 cromossomos, esta espécie apresentou 20 cromossomos.

De onze pares cromossômicos observados, cinco deles apresentaram configurações de pareamento em bastão, e seis em anel (Figura 1A). Porém, Sasikala e Paramathma (2010) encontraram apenas 
4 pares cromossômicos em anel. No presente trabalho, o índice de recombinação foi estimado em 14,25, considerado baixo quando comparamos com relatos de Koella (1993), que avaliando 15 famílias botânicas, observou que o índice de recombinação para estas famílias obteve uma média de 26,9. De acordo com Lawrence (1985) espécies de Senecio com predomínio de polinização cruzada apresentaram índices de recombinação inferiores às espécies autógamas do mesmo gênero, correlacionando dessa forma, índice de recombinação com sistema reprodutivo. Espera-se que a espécie aqui trabalhada apresente predomínio de polinização cruzada, por ser monóica, porém, pela escassez de trabalhos conclusivos sobre o sistema reprodutivo de $J$. curcas e de espécies relacionadas, qualquer inferência, neste momento, sobre a discussão acima será precoce.

Com base nas análises aqui realizadas, constatouse que a espécie $J$. curcas apresentou apenas um par de cromossomos associado ao nucléolo (Figura 1A). Mergonar, Karsburg e Bona (2010), via coloração com nitrato de prata, localizaram RON's nos pares cromosômicos 1 e 3 de $J$. curcas, e Dahmer, Wittmann e Dias (2009), apesar de dificuldades na visualização de constrições secundárias, informaram que havia a possibilidade de existir apenas um par cromossômico com presença dos RON'S nas células analisadas desta mesma espécie. Em espécies diplóides, como no caso de J. curcas, espera-se que haja apenas um par cromossômico contendo RON's. Damasceno Junior et al. (2009) localizaram, através análise de cariótipo, apenas um par cromossômico contendo constrições secundárias em Carica papaya e Vasconcellea monóica, ambas espécies diplóides.
Observou-se, no presente estudo, que a meiose de $J$. curcas apresentou algumas irregularidades, tais como a ocorrência de citomixia, de cromossomos pegajosos, de células contendo micronúcleos, e produtos meióticos irregulares, como tríades e díades.

No presente artigo observou-se uma expressiva taxa de citomixia e grãos de pólen de tamanhos distintos. Estas duas situações podem ocasionar diferenças no conteúdo genético celular e, portanto, podem contribuir para a geração de indivíduos poliplóides, euplóides e aneuplóides. $\mathrm{Na}$ Tabela 1, pode-se observar que a citomixia (Figuras $1 \mathrm{C} \mathrm{e}$ 1E) foi detectada em $21,16 \%$ de todas as células em divisão celular avaliadas, principalmente durante a prófase I. A citomixia também ocorreu em $0,43 \%$ dos micrósporos e em $12,21 \%$ de todas as tétrades avaliadas. Sendo assim, os genótipos estudados apresentaram grande incidência desta irregularidade. No presente estudo, foram observados a presença de canais interligando duas, três e quatro células simultaneamente, indicando a ocorrência de citomixia na espécies estudada. Falistocco, Tosti e Falcinelli (1995) observaram que esta irregularidade sempre ocorria de uma célula doadora para uma célula receptora e que, em alguns casos, a migração de DNA era completa, e poucos cromossomos permaneciam nas células doadoras. Já em outros casos, a conexão citoplasmática parecia ocorrer entre várias células ao mesmo tempo, sendo que, umas funcionavam como doadoras e outras como receptoras. Em tecidos da antera de tabaco, Wang et al. (2004) observaram que uma célula mãe de grão de pólen pode aceitar material genético de uma célula via canal citomítico enquanto direciona seu material para outra célula vizinha, tal fenômeno também foi observado no presente trabalho. 
Figura 1. Meiose e viabilidade polínica em Jatropha curcas. A) Célula em início de diacinese evidenciando 11 II, sendo que apenas um II está associado ao nucléolo (seta); B) Célula com cromossomos pegajosos; C) Células apresentando citomixia; D) Célula com a presença de micronúcleos (setas); E) Díade apresentando citomixia; F) Tríade; G) Tétrade; H) Grãos de pólen viável (seta maior) e inviável (seta menor). Figuras A, B e D ampliação de 1000x; Figuras C, E, F e G ampliação de 400x; Figura H ampliação de 100x.
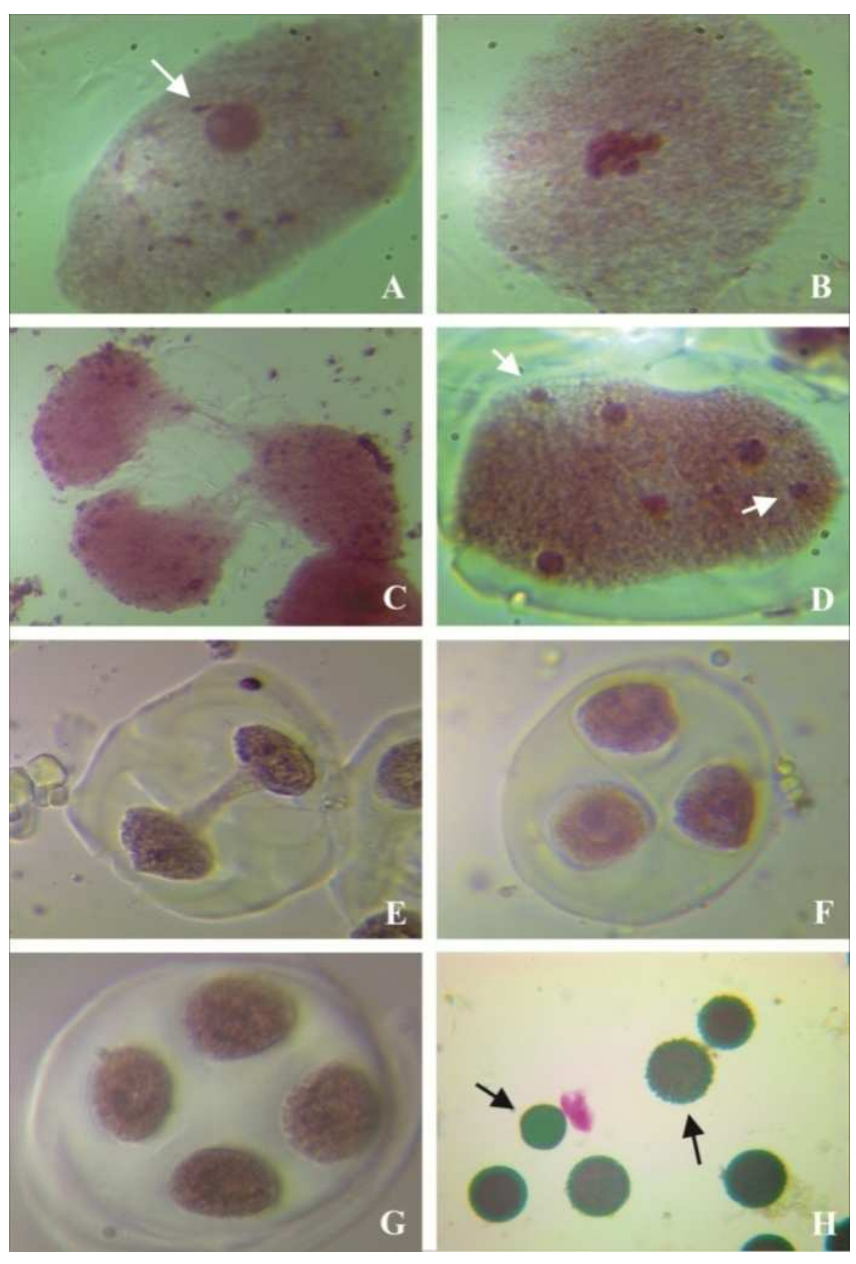

Fonte: Elaboração dos autores.

Análises citogenéticas realizadas em milho evidenciam que a citomixia pode estar sob controle genético, sendo esta irregularidade encontrada somente em alguns genótipos da espécie. Tais resultados demonstram que, em milho, a citomixia é genótipo-dependente (SOUZA et al., 2010).

De acordo com Kumar et al. (2010) e Ferreira et al. (2009), a citomixia pode resultar em esterilidade parcial, além de proporcionar a formação de grãos de pólen com tamanhos variados. No entanto, outros estudos apontam que plantas que apresentam citomixia também podem exibir alta taxa de viabilidade polínica, como observado em Dactylis glomerata, por Falistocco, Tosti e Falcinelli (1995), bem como apresentar taxas normais de produção de sementes (SONG; LI, 2009). 
Tabela 1. Irregularidades meióticas e Índice meiótico em Jatropha curcas.

\begin{tabular}{cc}
\hline Características & Valores percentuais \\
\hline Índice de recombinação & 14,25 \\
Cromossomos pegajosos & 10,62 \\
Citomixia entre micrósporos & 0,43 \\
Citomixia entre células em divisão celular & 21,16 \\
Citomixia em tétrades & 12,21 \\
Células com presença de micronúcleos & 52,36 \\
Índice meiótico & 84,21 \\
Mônades & 0,96 \\
Díades & 1,65 \\
Tríades & 12,25 \\
Políades & 0,89 \\
Viabilidade polínica & 89,85 \\
\hline
\end{tabular}

Fonte: Elaboração dos autores.

No presente trabalho, observou-se que $10,62 \%$ das células apresentaram cromossomos pegajosos (Figura 1B e Tabela 1). A ocorrência de cromossomos pegajosos pode ser provocada por processos aneugênicos e mutações em proteínas importantes na compactação da cromatina (LEVAN, 1938), ou ainda por fatores abióticos como altas temperaturas e herbicidas (CAETANO-PEREIRA; PAGLIARINI; CHAVES, 1995). De acordo com Damasceno Junior et al. (2010), a presença de cromossomos pegajosos pode provocar irregularidades na segregação dos cromossomos em meiose I e II, o que pode acarretar desbalanceamento cromossômico durante a divisão, e por sua vez, a produção de grãos de pólen inviáveis. Em J. tanjorensis Prabakaran e Sujatha (1999) observaram a ocorrência de diversas anormalidades durante a meiose, como por exemplo pareamentos uni e trivalentes em metáfase I, bem como a presença de cromossomos retardatários, sugerindo, segundo estes autores, a formação de produtos meióticos irregulares. Damasceno Junior et al. (2010) também observaram a presença de cromossomos retardatários em Carica papaya e Vasconcellea monoica.

Observa-se, na Tabela 1, que em 52,36\% das células no final da telófase apresentaram micronúcleos (Figura 1D). Esta alta ocorrência de micronúcleos pode estar ligada ao fenômeno da citomixia, cujas células avaliadas também apresentaram expressivos índices. Utsunomiya, Pagliarini e Valle (2004) e Boldrini, Pagliarini e Valle (2006) observaram em seus estudos que a citomixia pode ser responsável pela formação de micronúcleos nas células, principalmente quando ela está associada com a prófase. Risso-Pascotto, Pagliarini e Valle (2009) observaram em Brachiaria dura, células em telófase I que apresentavam micronúcleos resultantes da paralisação da meiose em células que sofreram citomixia. Outras irregularidades também provocam a formação de micronúcleos, Kiihl et al. (2010) relatam que cromossomos com migração precoce em metáfases e atrasos em anáfases não conseguem ser inclusos no núcleo telofásico, gerando assim a formação de micronúcleos. No presente trabalho não foram observados a presença de cromossomos precoces ou retardatários, porém, mesmo assim, não se pode descartar o envolvimento desta anomalia na geração de micronúcleos. Considerando que, no presente trabalho, a citomixia tenha sido a principalmente geradora das células com micronúcleos, é esperado uma percentagem superior de células individualizadas com micronúcleos em relação a percentagem de células envolvidas em citomixia, visto que grande parte destas últimas estavam ainda 
sob a condição de micrósporo ou em divisão celular, e desta forma todo o DNA deslocado de uma célula para outra serão distribuídos ao acaso em novas células geradas ao final da meiose I e II.

Além das causas anteriormente discutidas, fatores abióticos, alguns princípios ativos presentes em herbicidas e presença de metais pesados no solo também podem levar a fragmentação do material genético gerando células com micronúcleos. A partir disto, se fazem necessários estudos mais específicos sobre suas causas e consequências, uma vez que o material contido nestes micronúcleos pode vir a influenciar a expressão gênica no DNA nuclear, mitocondrial e cloroplastídico. Este fato pode ainda gerar implicações evolutivas muito importantes, podendo alterar a variabilidade dos meiósporos produzidos, influenciando na viabilidade e no nível de ploidia dos grãos de pólen.

\section{Índice meiótico}

Oíndice meiótico foi em média de 84,21\% (Tabela 1). De acordo com Love (1951), genótipos que apresentam índice meiótico abaixo de $90 \%$ podem resultar problemas reprodutivos quando envolvidos em cruzamentos, pois são considerados instáveis citologicamente, e isto pode vir a gerar dificuldades durante cruzamentos. No presente trabalho observou-se um índice meiótico abaixo do índice ótimo preconizado por Love (1951), demonstrando que $J$. curcas ainda não se constitui em uma espécie melhorada para a presente característica, porém não se pode deixar de mencionar que os valores aqui obtidos foram relativamente próximos do mínimo preconizado por Love. Nas Figuras 1F e $1 \mathrm{G}$ são apresentadas imagens de tríades e tétrades, respectivamente.

Damasceno Junior et al. (2010) trabalhando com espécies da família Caricaceae observaram maior índice meiótico para a espécie cultivada quando comparado com a espécie silvestre, respectivamente, C. papaya e $V$. monoica. Estudos realizados por Pozzobon et al. (2011), com doze linhagens de Capsicum, observaram índice meiótico com grande amplitude de valores, variando de 100 a 79,53\%. Estes valores foram devidos derivam de a anormalidades irregularidades, como a presença de micrócitos que provem da eliminação de cromossomos que ocorreram sob a forma de micronúcleos em fases anteriores a da meiose (POZZOBON; SCHIFINO-WITTMANN, 2006).

\section{Viabilidade polínica}

A porcentagem média de viabilidade polínica (Figura 1H) foi de 89,85 (Tabela 1). De 20 genótipos analisados apenas 5 apresentaram valores de viabilidade abaixo do valor médio (UFRRJ899; UFRRJ362;UFRRJ828; UFRRJ805; UFRRJ885). A menor viabilidade polínica encontrada no presente trabalho foi de 78\% (UFRRJ885), enquanto que o máximo observado foi de 96\% (UFRRJ861), ambos de Janaúba, MG. Estes dados demonstram que a espécie apresenta uma razoável variabilidade genética para esta característica nas condições ambientais onde o presente trabalho foi conduzido. Prabakaran e Sujatha (1999) observaram completa esterilidade masculina através da corabilidade dos grãos de pólen em J. tanjorensis.

De forma geral, observou-se coerência entre as estimativas do índice meiótico e a viabilidade polínica, o que é sempre esperado, visto que a porcentagem da viabilidade polínica é resultado dos acontecimentos durante a divisão celular, na qual é refletida pelo índice meiótico. Apesar das estimativas da porcentagem do índice meiótico e da viabilidade polínica ser levemente distintas, não se pode inferir que estas estimativas foram diferentes, visto que estas foram adquiridas através da contagem de células nas lâminas avaliadas e, assim, leves diferenças são esperadas de ocorrer. Conforme Loguercio e Battistin (2004) são observadas diferenças na viabilidade de pólen entre plantas da mesma variedade ou cultivares, ou ainda entre diferentes épocas de coleta, porém esta é predominante entre genótipos distintos. 
Damasceno Junior et al. (2010) recomendam que apenas genótipos que apresentem médias altas de viabilidade polínica e índice meiótico sejam incorporados em trabalhos de melhoramento genético que envolvam cruzamentos. Podese concluir que a coleção de germoplasma de Jatropha curcas da UFRRJ apresenta viabilidade polínica satisfatória, porém, existe variabilidade genética para esta característica entre os genótipos avaliados. Portanto, a seleção de genótipos de maior viabilidade polínica deve ser feita em conjunto com outros aspectos.

\section{Agradecimentos}

Agradecemos à FAPERJ pelos recursos financeiros e pela concessão de bolsa.

\section{Referências}

ACHTEN, W. M. J.; NIELSEN, L. R.; AERTS, R.; LENGKEEK, A. G.; KJAER, E. D.; TRABUCCO, A.; HANSEN, J. K.; MAES, W. H.; GRAUDAL, L.; AKINNIFESI, F. K.; MUYS, B. Towards domestication of Jatropha curcas. Biofuels, London, v. 1, n. 1, p. 91107, 2010.

ALEXANDER, M. P. Differential staining of aborted and non aborted pollen. Biotechnic \& Histochemestry, London, v. 44, n. 3, p. 117-122, 1969.

ARRUDA, F. P.; BELTRÃO, N. E. M.; ANDRADE, A. P.; PEREIRA, W. E.; SEVERINO, L. S. Cultivo de pinhão-manso (Jatropha curcas) como alternativa para o semi-árido nordestino. Revista Brasileira de Oleaginosas e Fibrosas, Campina Grande, v. 8, n. 1, p. 789-799, 2004.

BIONDO, E.; BATTISTIN, A. Comparação da eficiência de diferentes corantes na estimativa de viabilidade de grãos de pólen em espécies do gênero Eriosema (DC.) G. Don e Rhynchosia Lour (Leguminosae - Faboideae), nativas da região sul do Brasil. Bioikos, Campinas, v. 15, n. 1, p. 39-44, 2001.

BIONE, N. C. P.; PAGLIARINI, M. S.; TOLEDO, J. F. F. Meiotic behavior of several Brazilian soybean varieties. Genetics and Molecular Biology, Ribeirão Preto, v. 23, n. 3, p. 623-631, 2000.

BOLDRINI, K. R.; PAGLIARINI, M. S.; VALLE, C. B. Cell fusion and cytomixis during microsporogenesis in Brachiaria humidicola (Poaceae). South African Journal of Botany, Grahamstown, v. 72, n. 3, p. 478-481, 2006.

CAETANO-PEREIRA, C. M.; PAGLIARINI, M. S.; CHAVES, L. J. Influence of aluminium in causing stickness in maize microsporocytes. Maydica, Bergamo, v. 40, n. 1, p. 325-330, 1995.

CARVALHO, C. R.; CLARINDO, W. R.; PRAÇA, M. M.; ARAÚJO, F. S.; CARELS, N. Genome size, base composition and karyotype of Jatropha curcas L., an important biofuel plant. Plant Science, Philadelphia, v. 174, n. 6, p. 613-617, 2008.

DAHMER, N.; WITTMANN, M. T. S.; DIAS, L. A. S. Chromossome numbers of Jatropha curcas L.: an important agrofuel plant. Crop Breeding and Applied Biotechnology, Londrina, v. 9, n. 4, p. 386-389, 2009.

DAMASCENO JUNIOR, P. C.; COSTA, F. R. da; PEREIRA, T. N. S.; FREITAS-NETO, M.; PEREIRA, M. G. Karyotype determination in three Caricaceae species emphasizing the cultivated form (C. papaya L.). Caryologia, Firenze, v. 62, n. 1, p. 10-15, 2009.

DAMASCENO JUNIOR, P. C.; PEREIRA, T. N. S.; FREITAS-NETO, M.; PEREIRA, M. G. Meiotic behavior of Carica papaya and Vasconcellea monoica. Caryologia, Firenze, v. 63, n. 1, p. 229-236, 2010.

DARLINGTON, C. D. Evolution of genetics systems. 2. ed. Edinburgh: Oliver and Boyd, 1958. 256 p.

DEHGAN, B.; WEBSTER, G. L. Morphology and infrageneric relationships of the genus Jatropha (Euphorbiaceae). USA: University of California Press, $1979.73 \mathrm{p}$.

DRUMOND, M. A.; SANTOS, C. A. F.; OLIVEIRA, V. R. de; MARTINS, J. C.; ANJOS, J. B. dos; EVANGELISTA, M. R. V. Desempenho agronômico de genótipos de pinhão-manso no semi-árido pernambucano. Ciência Rural, Santa Maria, v. 40, n. 1, p. 44-47, 2010.

FALISTOCCO, E.; TOSTI, N.; FALCINELLI, M. Cytomixis in pollen mother cells of diploid Dactylis, one of origins of $2 \mathrm{n}$ gametes. Journal of Heredity, Oxford, v. 86, n. 6, p. 448-453, 1995.

FERREIRA, K.; TORRES, G. A.; CARVALHO, I. V.; DAVIDE, L. C. Abnormal meiotic behavior in three species of Crotalaria. Pesquisa Agropecuária Brasileira, Brasília, v. 44, n. 12, p. 1641-1646, 2009.

HELLER, J. Physic nut. (Jatropha curcas L.): promoting the conservation and use of underutilized and neglected crops. Rome: Institute of Plants Genetics and Crops Research, 1996. 66 p.

HORNER, H. T.; PALMER, R. G. Mechanisms of genetic male sterility. Crop Science, Madison, v. 35, n. 6, p. 1527-1535, 1995. 
KIIHL, P. R. P.; BARRAGAN, M. F.; SANTOS, S. P.; GODOY, S. M.; ALONSO-PEREIRA, A. R.; STENZEL, N. M. C.; RISSO- PASCOTTO, C. Abnormal behavior of spindle during microsporogenesis of Passiflora (Passifloraceae). Arquivos de Ciência de Saúde da UNIPAR, Umuarama, v. 14, n. 3, p. 237-243, 2010.

KOELLA, J. C. Ecological correlates of chiasma frequency and recombination index of plants. Biological Journal of the Linnean Society, London, v. 48, n. 3, p. 227-238, 1993.

KUMAR, P.; SINGHAL, V. K.; KAUR, D.; KAUR, S. Cytomixis and associated meiotic abnormalities affecting pollen fertility in Clematis orientalis. Biologia Plantarum, Heidelberg, v. 54, n. 1, p. 181-184, 2010.

LAWRENCE, M. E. Senecio L. (Asteraceae) in Australia: Reproductive biology of a genus found primarily in unstable environments. Australian Journal of Botany, Collingwood, v. 33, n. 2, p. 197-208, 1985.

LEVAN, A. The effect of colchicine on root mitosis in Allium. Hereditas, Sweden, v. 24, n. 4, p. 471-486, 1938.

LOGUERCIO, A. P.; BATTISTIN, A. Microsporogênese de nove acessos de Syzygium cumini (L.) Myrtaceae e oriundos do Rio Grande do Sul-Brasil. Revista da Faculdade de Zootecnia, Veterinária e Agronomia, Uruguaiana, v. 11, n. 1, p. 192-205, 2004.

LOVE, R. M. Varietal differences in meiotic chromosomes behavior of Brazilian wheats. Agronomy Journal, Madison, v. 43, n. 2, p. 72-76, 1951.

MERGONAR, M. A. S.; KARSBURG, I. V.; BONA, D. A. O. Identificação da região organizadora nucleolar de “Jatropha curcas L.". Estudos, Goiânia, v. 37, n. 5, p. 755-76, 2010.

POZZOBON, M. T.; SCHIFINO-WITTMANN, M. T. A meiotic study of the wild and semi-domesticated Brazilian species of genus Capsicum L. (Solanaceae). Cytologia, v. 71, n. 3, p. 275-287, 2006.

POZZOBON, M. T.; SOUZA, K. R. R.; CARVALHO, S. I. C.; REIFSCHNEIDER, F. J. B. Meiose e viabilidade polínica em linhagens avançadas de pimenta. Horticultura Brasileira, Brasília, v. 29, n. 2, p. 212-216, 2011.
PRABAKARAN, A. J.; SUJATHA, M. Jatropha tanjorensis Ellis and Saroja, a natural interspecific hybrid occurring in Tamil Nadu, India. Genet Resources Crop Evolution, Netherlands, v. 46, p. 213-218, 1999.

RISSO-PASCOTTO, C.; PAGLIARINI, M. S.; VALLE, C. B. Chromosome number and microsporogenesis of two accessions of Brachiaria dura Stapf (Poaceae). Biota Neotropica, Campinas, v. 9, n. 2, p. 257-261, 2009.

ROSADO, T. B.; LAVIOLA, B. G.; FARIA, D. A.; PAPPAS, M. C. R.; BHERING, L. L.; QUIRINO, B.; GRATTAPAGLIA, D. Molecular markers reveal limited genetic diversity in a large germplasm collection of the biofuel crop Jatropha curcas L. in Brazil. Crop Science, Madison, v. 50, n. 6, p. 2372-2382, 2010.

SASIKALA, R.; PARAMATHMA, M. Chromosome studies in the genus Jatropha L. Electronic Journal of Plant Breeding, New Delhi, v. 1, n. 4, p. 637-642, 2010.

SONG, Z. Q.; LI, X. F. Cytomixis in pollen mother cells of Salvia miltiorrhiza. Caryologia, v. 62, n. 3, p. 213219, 2009.

SOUZA, V. F.; PAGLIARINI, M. S.; SCAPIM, C. A.; RODOVALHO, M.; FARIA, M. V. Meiotic behavior as a selection tool in silage corn breeding. Genetics and Molecular Research, Ribeirão Preto, v. 9, n. 4, p. 20962103, 2010.

SUN, Q. B.; LI, L. F.; LI, Y.; WU, G. J.; GE, X. J. SSR and AFLP markers reveal low genetic diversity in the biofuel plant Jatropha curcas in China. Crop Science, Madison, v. 48, n. 5, p. 1865-1871, 2008.

UTSUNOMIYA, K. S.; PAGLIARINI, M. S.; VALLE, C. B. Chromosome transfer among meiocytes in Brachiaria nigropedata (Ficalho \& Hiern) Stapf (Gramineae). Cytologia, v. 69, n. 4, p. 395-398, 2004.

WANG, X. Y.; YU, C. H.; LI, X.; WANG, C. Y.; ZHENG, G. C. Ultrastructural aspects and possible origin of cytoplasmic channels providing intercellular connection in vegetative tissues of anthers. Russian Journal of Plant Physiology, v. 51, n. 1, p. 97-106, 2004. 